\title{
Further evidence for paternal inheritance of mitochondrial DNA in the sheep (Ovis aries)
}

\author{
X Zhao ${ }^{1}, \mathrm{~N} \mathrm{Li}^{2}, \mathrm{~W} \mathrm{Guo}{ }^{1}, \mathrm{X} \mathrm{Hu}{ }^{2}, \mathrm{Z} \mathrm{Liu}{ }^{2}, \mathrm{G} \mathrm{Gong}^{2}$, A Wang ${ }^{1}$, J Feng ${ }^{2}$ and $\mathrm{C} \mathrm{Wu}^{1}$ \\ ${ }^{1}$ Department of Animal Science and Technology, China Agricultural University, Beijing 100094, China; ${ }^{2}$ National Laboratories for \\ Agrobiotechnology, China Agricultural University, Beijing 100094, China
}

\begin{abstract}
The mitochondrial DNA of 172 sheep from 48 families were typed by using PCR-RFLP, direct amplification of the repeated sequence domain and sequencing analysis. The mitochondrial DNA from three lambs in two half-sib families were found to show paternal inheritance. Our findings provide direct evidence of paternal inheritance of mitochondria DNA in sheep. A total of 12 highly polymorphic
\end{abstract}

microsatellite markers, which mapped on different chromosomes, were employed to type the sheep population to confirm family relationships. Possible mechanisms of paternal inheritance are discussed.

Heredity (2004) 93, 399-403. doi:10.1038/sj.hdy.6800516

Published online 21 July 2004

Keywords: mitochondrial DNA; PCR-RFLP; paternal inheritance; microsatellite markers

\section{Introduction}

Mitochondrial DNA (mtDNA) is the only extranuclear genome in the animal cytoplasm, and exists as multiple copies with a high mutation rate. Mammalian mtDNAs include 37 genes, including 13 polypeptide-encoding genes, 22 tRNA genes and two rRNA genes, which encode essential components of oxidative phosphorylation (OXPHOS) in mitochondrial inner membrane, generating cellular energy in the main form of adenosine triphosphate (ATP). In recent years, the structure and function of mtDNAs have been a popular area of research in molecular evolution, classification, population genetic analysis, the identification of relatives, forensic science, aging, disease diagnosis, apoptosis and the analysis of quantitative trait loci (QTL) (Albuquerque et al, 1998; Wallace, 1999; Gray et al, 1999; Sutovsky and Schatten, 2000).

Animal mtDNA has been thought to be strictly following maternal inheritance. A typical experiment was the study of the mtDNA RFLP of the reciprocal hybrid lines between horse (Equus caballus) and donkey (Equus asinus). The mules' mtDNA patterns were identical to those of the horse, while the hinnies exhibited a pattern identical to the donkey (Hutchison et al, 1974). However, evidence for occasional paternal inheritance has been reported in animals including the fruit fly Drosophila melanogaster (Kondo et al, 1992), human Homo sapiens (Schwartz and Vissing, 2002), mouse Mus musculus (Gyllensten et al, 1991; Shitara et al, 1998), cattle Bos Taurus (Steinborn et al, 1998), Lepidopteran insects (Lansman et al, 1983) and honeybee Apis mellifera $L$ (Meusel and Moritz, 1993). In the marine mussel

Correspondence: N Li, National Laboratories for Agrobiotechnology, China Agricultural University, Beijing 100094, China.

E-mail: ninglbau@public3.bta.net.cn

Received 15 April 2003; accepted 15 October 2003; published online 21 July 2004
Mytilus edulis, the paternal mtDNA was proven to be more extensive (Sutherland et al, 1998).

The complete mtDNA sequence has been determined in sheep (Hiendleder et al, 1998). The displacement loop region (D-loop) is the noncoding control region of the mtDNA, and plays an important role in replication and transcription. Within the D-loop there is a tandem repeated sequence region with a motif, $75 \mathrm{bp}$ in length, sited between the Pro-tRNA gene and a conserved sequence block 1 (CSB 1) (Zardoya et al, 1995). Paternal inheritance in an ovine family (named Pmt family) was reported by Zhao et al (2001), but the pedigree of Pmt family was not checked. In this work, we traced the ewe in the Pmt family and found the ewe mated with a randomly selected ram produced another family, which again showed paternal mtDNA inheritance. To confirm the paternal inheritance in these families, we have investigated not only by checking DNA polymorphisms in mtDNA D-loop (within the non-coding region) and in COI gene (within the coding region) but also by the direct sequencing of the repeated region in the mtDNA D-loop. Subsequently, the pedigree of the Pmt families was also checked with 12 highly polymorphic microsatellite markers to confirm blood relationship. Our work has provided further solid evidence for paternal inheritance of mtDNA in the sheep.

\section{Materials and methods}

\section{DNA samples}

Blood samples from 172 sheep of 48 hybrid families produced by the Dorset breed (male line) crossed to the Small-tail Han breed (female line, a Chinese local breed) were collected and preserved in ACD buffer until DNA purification with SDS, proteinase $\mathrm{K}$ and phenol. DNA was isolated from the whole blood using standard SDS/ proteinase $\mathrm{K}$ methods and phenol/chloroform extractions (Sambrook et al, 1989). 
Analysis of mtDNA

In all, $50 \mu \mathrm{l}$ of each PCR mixture containing $100 \mathrm{ng}$ of total DNA, $50 \mathrm{pmol}$ of each primer, $50 \mu \mathrm{l}$ of $10 \times \mathrm{Taq}$ polymerase buffer solution and $1 \mathrm{U}$ of Taq polymerase for PCR was incubated in the thermal cycler (PE Amp2400, Peking-Elmer, USA). The primer sequences and products yielded are listed in Table 1, and the primers locations in the mtDNA D-loop are illustrated in Figure 1. Products were separated in $1 \%$ agarose gels in $1 \times \mathrm{TAE}$, $\mathrm{pH}$ 8.0. The excised fragments were purified with the Geneclean kit (Biolab LTD) and inserted in the pGem-T Easy vector (Promega, USA), following the protocols of the manufacturers. Clones were purified with the Geneclean kit and sequenced by an ABI 377 DNA sequencer. For each fragment, sequences were based on the analysis of two independent clones.
PCR-RFLP analysis

The PCR products cut from agarose gels were purified by Geneclean kit (Biolab LTD). Purified PCR product $(5 \mu \mathrm{l})$ was mixed with $2 \mathrm{U}$ restriction enzymes and $1.2 \mu \mathrm{l} 10$ fold buffer solution, and $\mathrm{ddH}_{2} \mathrm{O}$ was added until the total volume reached $12 \mu \mathrm{l}$. The mixture was incubated at $37^{\circ} \mathrm{C}$ for $4 \mathrm{~h}$.

\section{Microsatellite genotyping}

In order to confirm the paternity or maternity of each family, 12 highly polymorphic microsatellite markers distributed on nine chromosomes were scored using the method of Crawford et al, 1995). The nucleotide sequences of the primers are shown in Table 2.

Table 1 The primer nucleotide sequences and yielded products of mtDNA

\begin{tabular}{|c|c|c|c|}
\hline Primer names & Primer sequences & Yielded products & Fragment length of PCR products $/ b p$ \\
\hline $\begin{array}{l}\text { P1F } \\
\text { P4R }\end{array}$ & $\begin{array}{l}\text { 5'-CAACACCCAAAGCTGAAGTTC-3' } \\
\text { 5'-CTAGGCATTTTCAGTGCCTTGC-3' }\end{array}$ & D-loop & $963+75 n$ \\
\hline $\begin{array}{l}\text { P2F } \\
\text { P3R }\end{array}$ & $\begin{array}{l}\text { 5'-TTATGTCTGTCTTGAATGTGCT-3' } \\
\text { 5'-CCCTACATGCTTCAGTGAAGTG-3' }^{\prime}\end{array}$ & Repeated sequence region & $40+75 n$ \\
\hline $\begin{array}{l}\text { COIF } \\
\text { COIR }\end{array}$ & 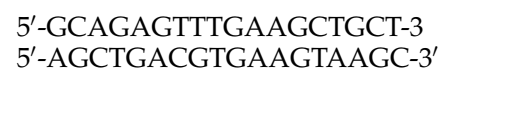 & $\begin{array}{l}\text { Partial COI } \\
\text { Partial tRNA }{ }^{\text {cys }} \\
\text { tRNA }^{\text {Tyr }}\end{array}$ & 1053 \\
\hline
\end{tabular}

$n$ : repeats number.

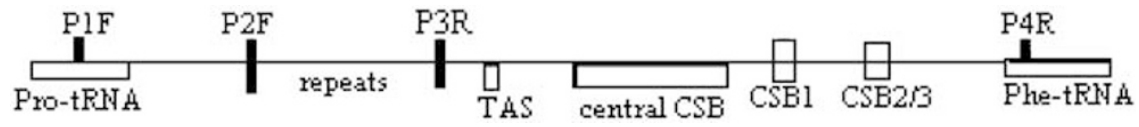

Figure 1 Structure of sheep mtDNA D-loop and the location of the primers. CSB, conserved sequence block; TAS, termination-associated sequence.

Table 2 The information of the nucleotide sequences of the primers

\begin{tabular}{|c|c|c|c|c|c|}
\hline Microsatellite & Primer $n t$ sequence & Het. (\%) & Chro. & Size $(b p)$ & Accession no. \\
\hline OarAE101 & $\begin{array}{l}\text { F: ttcttatagatgcactcaagctagg } \\
\text { R: taagaaatatattgaaaaaactgtatctccc }\end{array}$ & 75 & 6 & $99-123$ & L13692 \\
\hline OarHH55 & $\begin{array}{l}\text { F: gttattccatattctttcctccatcataagc } \\
\text { R: ccacacagcgcaactaaaacccagc }\end{array}$ & 64 & 6 & 119-139 & L13693 \\
\hline OarHH35 & $\begin{array}{l}\text { F: aattgcattcagtatctttaacatctggc } \\
\text { R: atgaaaatataaagagaatgaaccacacgg }\end{array}$ & 87 & 4 & 117-155 & L12554 \\
\hline IL2RA & $\begin{array}{l}\text { F: agcagaggtacaggtggtaagca } \\
\text { R: gatatgccttggagaaggtagcgtat }\end{array}$ & 70 & 13 & 172-192 & a \\
\hline MT2 & $\begin{array}{l}\text { F: tgaggaggattcgttaccgtctgag } \\
\text { R: ccgaggggcagcggattaag }\end{array}$ & 79 & 14 & $149-227$ & a \\
\hline CSSM31 & $\begin{array}{l}\text { F: ccaagtttagtacttgtaagtaga } \\
\text { R: gactctctagcactttatctgtgt }\end{array}$ & 79 & 23 & 172 & U03838 \\
\hline MAF4 & $\begin{array}{l}\text { F: aaaggtcttgactctgtgtcgg } \\
\text { R: tccacggggtctcaaagagtcg }\end{array}$ & 86 & 1 & $157-221$ & M61729 \\
\hline OARAE64 & $\begin{array}{l}\text { F: tgcaagaagggcagaccttggag } \\
\text { R: cagaccactctcttccctccacg }\end{array}$ & 89 & 7 & 122-158 & L13869 \\
\hline OARCP49 & $\begin{array}{l}\text { F: cagacacggcttagcaactaaacgc } \\
\text { R: gtggggatgaatattccttcataagg }\end{array}$ & 86 & 17 & $85-107$ & U15702 \\
\hline OARHH30 & $\begin{array}{l}\text { F: ctcagtctcaactttgttcctctatagc } \\
\text { R: gaaagctaaggctgaacattgtgccc }\end{array}$ & 79 & 2 & 103-117 & U08877 \\
\hline BMS2508 & $\begin{array}{l}\text { F: tttctgggattacaaaatgctc } \\
\text { R: tttcttaggggagtgttgattc }\end{array}$ & 67 & 6 & $92-118$ & G18959 \\
\hline BM143 & $\begin{array}{l}\text { F: acctgggaagcctccatatc } \\
\text { R: ctgcaggcagattctttatcg }\end{array}$ & 83 & 6 & $98-120$ & G18387 \\
\hline
\end{tabular}

\footnotetext{
${ }^{a}$ http://www.roslin.ac.uk/.
} 


\section{Results}

PCR-RFLP analysis of the mtDNA D-loop region

The PCR products from D-loop regions with the primers P1F and P4R were screened for polymorphism with digestion of 11 restriction enzymes (Table 3). RFLPs were detected and used in the evaluation of the genetic variation of sheep populations (data not shown here). Two half-sib families (named the Pmt family) produced within 3 years of each other were found to show paternal inheritance, which means that the mtDNA patterns of the progeny was identical to their father's (Figure 2, Figure 3, Figure 5). These two families share the same mother (named $\mathrm{M}$ ) but two different fathers (named F1 and F2), and one family has only one lamb (called P1) while the other has three lambs (called P2, P3 and P4, respectively). The PCR-RFLPs patterns of the mtDNA with the primer pair P1F and P4R in the Pmt family were distinguishable between the father's mtDNA (named P type) and the mother's mtDNA (named $M$ type) (Figure 2). The mtDNA of the progeny P1, P2 and P3 were from the father's side but that of P4 was from the mother's side. We suspected that the polymorphism was the result of repeat number variation. The primers P2F and P3R were designed to assess this interpretation. The PCR products were of two different lengths. One was $340 \mathrm{bp}$ in size $(40 \mathrm{bp}+75 \mathrm{bp} \times 4)$, derived from the father,

Table 3 PCR-RFLP of mtDNA D-loop in Pmt family

\begin{tabular}{lcc}
\hline Enzymes & \multicolumn{2}{c}{ Molecular size of restriction fragments $(\mathrm{bp})$} \\
\cline { 2 - 3 } & Type I & Type II \\
\hline AccI & 641,622 & 536,622 \\
AluI & $625,332,265,41$ & $550,332,265,41$ \\
ApaI & 691,572 & 616,572 \\
Bam $\mathrm{HI}$ & 668,595 & 593,595 \\
BanII & 691,572 & 616,572 \\
DpnI & $618,593,52$ & $543,593,52$ \\
DdeI & $679,362,207,15$ & $604,362,207,15$ \\
HaeIII & $689,357,144,63,10$ & $614,357,144,63,10$ \\
HapII & $685,229,349$ & $610,229,349$ \\
HincII & 669,594 & 669,519 \\
TaqI & 799,464 & 724,464 \\
\hline
\end{tabular}

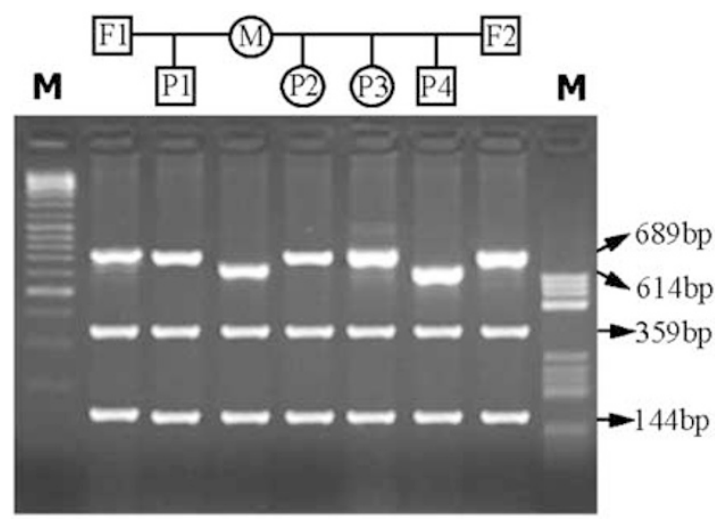

Figure 2 Patterns of mtDNA D-loop digested by HaeIII in Pmt family showing paternal inheritance of sheep mtDNAs. M lane is the $1 \mathrm{~kb}$ ladder marker.

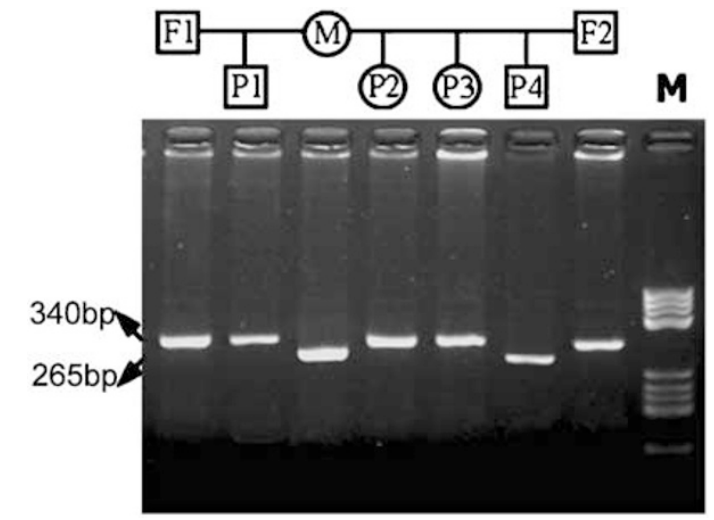

Figure 3 Amplification of the repeated region in Pmt family showing paternal inheritance of sheep mtDNAs. M lane is the $1 \mathrm{~kb}$ ladder marker.

and the other was $265 b p(40 b p+75 b p \times 3)$, derived from the mother. The amplification confirmed our interpretation of the RFCP pattern, and also the paternal origin of the mtDNA in three of the lambs (Figure 3). The PCR products of two types were sequenced, and the nucleotide sequence data indicate that the paternal type has four copies of the repeat motif, while the maternal type possessed only three copies of repeat motif (Figure 4).

\section{Sequence analysis of mtDNA coding region}

The CO I gene of mtDNA in Pmt family was also amplified with the primers COI F and COI R. When the PCR products were cut with Hinf I enzyme, PCR-RFLPs were obtained, which again showed that three lambs followed paternal inheritance (Figure 5). The restriction site alteration was confirmed by direct sequencing of the PCR products (Figure 5).

\section{Microsatellite analysis}

A total of 12 microsatellite markers were genotyped, which are highly polymorphic and follow strict Mendelian inheritance (Figure 6). The genotyping clearly confirmed the Pmt family's consanguineous relationships (Table 4).

\section{Discussion}

Reports of paternal inheritance of animal mtDNA have drawn close attention and suspicion. The accumulating evidence for the phenomenon has become relatively extensive however. There are two possible mechanisms that could explain the transmission of paternal mtDNA inheritance. One is paternal leakage of $\mathrm{mtDNA}$. Labeled mitochondria from mouse spermatids could be $80 \%$ in the one-cell zygote but fell to $25 \%$ in two-cell, $9 \%$ in fourcell and approximately $1 \%$ in eight-cell or late stages (Cummins et al, 1998). Paternal mtDNA can enter eggs with sperm, and might be maintained at low level in the fertilized eggs. The other possible mechanism is recombination of mtDNA into the nucleus. In several species, including human, chimpanzee and cats (Felis), mitochondrial genes have been incorporated into the nuclear genome, known as Numt DNA (Lopez et al, 1994; Wallace et al, 1997). Usually Numts have acted as pseudogenes in 
repeat I

repeat II

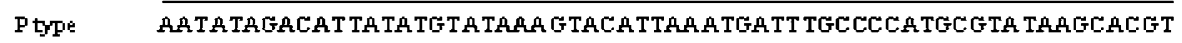

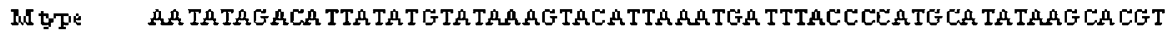

repeat III

\begin{tabular}{|c|c|}
\hline F tre & ACATAA CAT TAATÖTAATATAGACATTATA TGTATAAAGTACAT TAAATGATTTOCO \\
\hline M trpe & repeat IV \\
\hline Ptype & TGEC̈TA TAAGCACGTA CA TAA CA T TAA TGTAA TA TA GACATTA TA TǴTATAAAGTA CA \\
\hline M tres & TA TATTAA T GAATA TAGACATTA TATGTA TAAAG TACA \\
\hline type & AAA TGATTTA CCCCATGCGTATA GGCATGTA CA TTCACTTCAC TGAAG CA TGTAGG G \\
\hline W trpe & AAA TGATTTA CC CCATGCGTATAAGCATGTA CA TTEACTTCAC TGAAGCATATAGG \\
\hline
\end{tabular}

Figure 4 Nucleotide sequence comparison of the repeated region in D-loop between the M-type and the P-type sheep. Dashes indicate deleted base pairs and the primer is in the box.

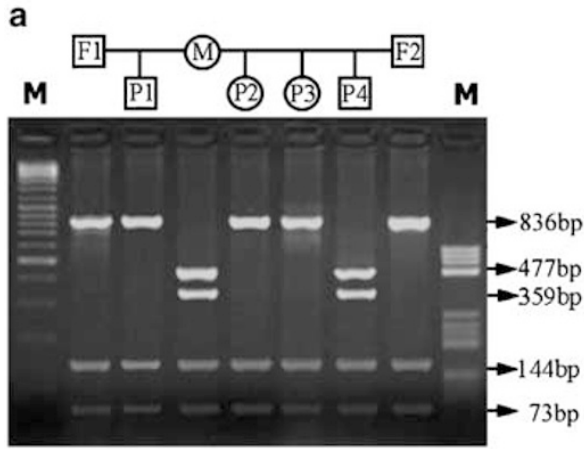

b

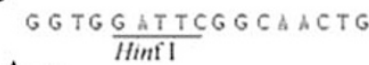

A

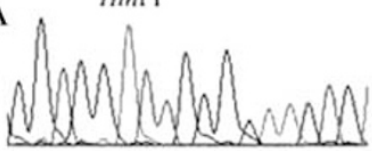

G GTGGATTTGGCA ACTG

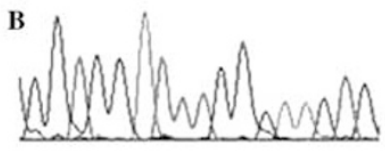

Figure 5 Polymorphic cleavage site of Hinf I in the sheep. CO I gene reveals paternal inheritance. M1 is the $1 \mathrm{~kb}$ ladder marker. M2 is the PBR322/HaeIII marker. A and B represent the type A and type B of ovine mtDNA, respectively.

nuclear genome, but there is a possibility of interaction between nuclear and mitochondrial DNA, and it is conceivable that Numts could be transferred back to the mtDNA. It has been reported that the extensive recombination occurred between mtDNAs (Hagelberg et al, 1999). Awadalla et al (1999) suggest that such recombination most likely happens between paternal and maternal mtDNAs.

We report here the paternal inheritance of ovine mtDNA in two related hybrid families produced by Dorset crossed to Small Tail Han sheep. The phenomena was identified by PCR-RFLPs in the D-loop region and the $\mathrm{CO}$ I gene, by further amplification and direct sequencing. No heteroplasmy of mtDNA has been detected from these sheep although this has been reported in other animals such as bat, horse, seal, rabbit and pig. Both maternal and paternal mtDNAs were found in different offspring. We suggest that both parent's mtDNAs might be present at an early stage but that only one survives to later development. However, the mechanism for such a process remains to be elucidated.

The occasional paternal inheritance seen suggests that the effects of paternal mtDNA should be considered as a genetic factor that could influence evolution, disease development and production traits in animals. 
Table 4 The genotypes of each marker locus in Pm families

\begin{tabular}{|c|c|c|c|c|c|c|c|}
\hline Microsatellite & $F 1$ & $P 1$ & $M$ & $P 2$ & P3 & $P 4$ & $F 2$ \\
\hline CSSM31 & $178 / 178$ & $178 / 178$ & $178 / 178$ & $172 / 178$ & $172 / 178$ & $172 / 178$ & $172 / 172$ \\
\hline MT2 & $150 / 150$ & $150 / 150$ & $150 / 150$ & $147 / 150$ & $147 / 150$ & $147 / 150$ & $147 / 147$ \\
\hline IL2RA & $178 / 192$ & $178 / 192$ & $178 / 192$ & $178 / 192$ & $178 / 192$ & 178/192 & $178 / 178$ \\
\hline OARAE64 & $130 / 130$ & $130 / 130$ & $130 / 130$ & $124 / 130$ & $124 / 130$ & $124 / 130$ & $124 / 124$ \\
\hline MAF4 & $221 / 221$ & $221 / 221$ & $221 / 221$ & $205 / 221$ & $205 / 221$ & $205 / 221$ & $205 / 205$ \\
\hline OARCP49 & $107 / 107$ & $107 / 107$ & $107 / 107$ & $95 / 107$ & $95 / 107$ & $95 / 107$ & $95 / 95$ \\
\hline OARHH30 & $113 / 117$ & $117 / 117$ & $117 / 117$ & $103 / 117$ & $103 / 117$ & $103 / 117$ & $103 / 103$ \\
\hline OARAE101 & $103 / 103$ & $97 / 103$ & $97 / 97$ & $97 / 109$ & $97 / 109$ & $97 / 109$ & $109 / 109$ \\
\hline BM143 & $106 / 110$ & $106 / 106$ & $106 / 110$ & $102 / 110$ & $110 / 110$ & $110 / 110$ & $102 / 110$ \\
\hline BMS2508 & $100 / 112$ & $100 / 112$ & $94 / 112$ & $110 / 112$ & $94 / 100$ & $94 / 100$ & $100 / 110$ \\
\hline OARHH35 & $127 / 127$ & $127 / 137$ & $137 / 137$ & $127 / 137$ & $137 / 137$ & 137137 & $127 / 137$ \\
\hline OARHH55 & $124 / 148$ & $124 / 148$ & $148 / 148$ & $124 / 148$ & $148 / 148$ & $124 / 148$ & $124 / 148$ \\
\hline
\end{tabular}

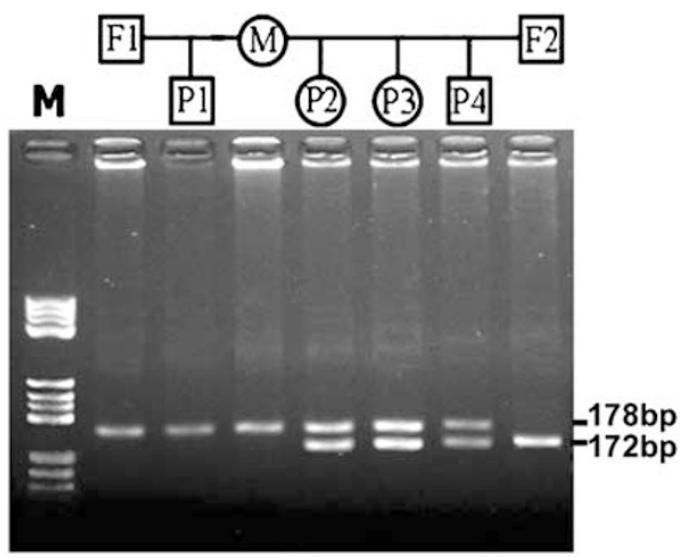

Figure 6 Representative genotyping of the microsatellite marker CSSM31 in the Pmt sheep family. $M$ is the $1 \mathrm{~kb}$ ladder marker.

\section{Acknowledgements}

This work is supported by National Major Basic Research Program (Grant No.: G20000161) and Natural Scientific Foundation of China (Grant No.: 39730360). We also thank Dr Leif Andersson for a critical reading of this manuscript.

\section{References}

Albuquerque LG, Keown JF, Van Vleck LD (1998). Variances of direct genetic effects, maternal genetic effects, and cytoplasmic inheritance effects for milk yield, fat yield, and fat percentage. J Dairy Sci 81: 544-549.

Awadalla P, Eyre-Walker A, Smith JM (1999). Linkage disequilibrium and recombination in hominid mitochondrial DNA. Science 286: 2524-2525.

Crawford AM, Dodds KG, Ede AJ, Pierson CA, Montgomery (1995). An autosomal genetic linkage map of the sheep genome. Genetics 140: 703-724.

Cummins JM, Wakayama T, Yanagimachi R (1998). Fate of microinjected spermatid mitochondria in the mouse oocyte and embryo. Zygote 6: 213-222.

Gray MW, Burger G, Lang BF (1999). Mitochondrial evolution. Science 283: 1476-1481.

Gyllensten U, Wharton D, Josefsson A (1991). Paternal inheritance of mitochondrial DNA in mice. Nature 352: 255-257.

Hagelberg E, Goldman N, Lin P (1999). Evidence for mitochondrial DNA recombination in a human population of island Melanesia. Proc R Soc London B Biol Sci 266: 485-492.

Hiendleder S, Lewalski H, Wassmuth R., Janke A (1998). The complete mitochondrial DNA sequence of the domestic sheep (Ovis aries) and comparison with the other major ovine haplotype. J Mol Evol 47: 441-448.

Hutchison CA, Newbold JE, Potter SS (1974). Maternal inheritance of mammalian mitochondrial DNA. Nature 251: 536-538.

Kondo R, Matsuura ET, Chigusa SI (1992). Further observation of paternal transmission of Drosophila mitochondrial DNA by PCR selective amplification method. Genet Res 59: 81-84.

Lansman RA, Avise JC, Huettel MD (1983). Critical experimental test of the possibility of 'paternal leakage' of mitochondrial DNA. Proc Natl Acad Sci USA 80: 1969-1971.

Lopez JV, Yuhki N, Masuda R, Modi W, O'Brien SJ (1994). Numt, a recent transfer and tandem amplification of mitochondrial DNA to the nuclear genome of the domestic cat. J Mol Evol 39: 174-190.

Meusel MS, Moritz RF (1993). Transfer of paternal mitochondrial DNA during fertilization of honeybee (Apis mellifera L.) eggs. Curr Genet 24: 539-543.

Sambrook J, Fritsch EF, Maniatis T (1989). Molecular Cloning. A Laboratory Manual. Cold Spring Harbor Laboratory Press: Cold Spring Harbor, USA.

Schwartz M, Vissing J (2002). Paternal inheritance of mitochondrial DNA. $N$ Engl J Med 22: 576-580.

Shitara H, Hayashi JI, Takahama S, Kaneda H, Yonekawa H (1998). Maternal inheritance of mouse mtDNA in interspecific hybrids: segregation of the leaked paternal mtDNA followed by the prevention of subsequent paternal leakage. Genetics 148: 851-857.

Steinborn R, Zakhartchenko V, Jelyazkov J, Klein D, Wolf E, Muller $M$ et al (1998). Composition of parental mitochondrial DNA in cloned bovine embryos. FEBS Lett 426: 352-356.

Sutherland B, Stewart D, Kenchington ER, Zouros E (1998). The fate of paternal mitochondrial DNA in developing female mussels, Mytilus edulis: implications for the mechanism of doubly uniparental inheritance of mitochondrial DNA. Genetics 148: 341-347.

Sutovsky P, Schatten G (2000). Paternal contributions to the mammalian zygote: fertilization after sperm-egg fusion. Int Rev Cytol 195: 1-65.

Wallace DC (1999). Mitochondrial diseases in man and mouse. Science 283: 1482-1488.

Wallace DC, Stugard C, Murdock D, Schurr T, Brown MD (1997). Ancient mtDNA sequences in the human nuclear genome: a potential source of errors in identifying pathogenic mutations. Proc Natl Acad Sci USA 94: 14900-14905.

Zardoya R, Villalta M, Lopez-Perez MJ, Garrido-Pertierra A, Montoya J, Bautista JM (1995). Nucleotide sequence of the sheep mitochondrial DNA D-loop and its flanking tRNA genes. Curr Genet 28: 94-96.

Zhao X, Chu M, Li N, Wu C (2001). Paternal inheritance of mitochondrial DNA in the sheep (Ovisaries). Sci China (Ser C) 44: 321-326. 